\title{
Analysis of Dimensional Changes in the Lower Limbs During Movement for Sizing and Fit Development.
}

\author{
Kasey $\mathrm{HATCH}^{* 1}$, Anke KLEPSER ${ }^{2}$, Kristina BRUBACHER ${ }^{1}$, \\ Simeon GILL ${ }^{1}$, Anura FERNANDO ${ }^{1}$ \\ 1 University of Manchester, Manchester, UK; \\ 2 Hohenstein Laboratories, Bönnigheim, Germany \\ https://doi.org/10.15221/21.14
}

\begin{abstract}
The aim of this research is to improve sizing and fit of compression sports leggings for an athletic female population. Using 3D and 4D body scan technology, it is possible to understand how the body's dimensions change during movement, which can provide information to enhance the fit of compression garments, that are commonly worn for physical activity. The Hohenstein Institut collaborated with this research and conducted body scanning using their Vitus Smart Laser scanner and Little Alice 4D scanner. Six German amateur football players were recruited and scanned in two static postures and two corresponding dynamic postures. Dimensional changes around key measurements for pattern creation were analysed and compared. It was hypothesised that lower body dimensions would change substantially from the standard scan posture to the functional postures, and results would present a difference between the static functional postures and the dynamic posture.
\end{abstract}

Keywords: Body scanning, fit, compression, movement

\section{Introduction}

Three-dimensional (3D) body scanning can be used to analyse the human form, and extract body dimensions that can aid product development, which is becoming increasingly popular [1]. It can provide useful anthropometric data to understand body shape and size variations of a population, so that manufacturers of ready-to-wear apparel can create size designations that will offer the most appropriate fit for their target population. During a size survey or study, participants are required to be scanned in the standard 'relaxed' posture with arms and legs abducted by 20 degrees, to ensure the scan is with minimal occlusion [1]. However, this captures the body in one fixed posture, which does not represent postures assumed in reality [12]. This is an even bigger consideration for the development of sportswear, where the wearer will be constantly in motion and not often static. It is essential that when designing sports apparel that the application is understood; the movements performed by the end user as well as their environment can greatly affect how the garment needs to function [2]. Sports compression garments (SCGs) exert pressure on the body to enhance the wearer's performance and recovery and accurate fit is fundamental to their functionality [16]. The fit and therefore pressure delivery will be affected by the body's movement during physical activity, which is an area that is yet to be explored by researchers.

In this comparative study, which comprises of two parts, the aim was to identify whether fit and sizing of SCGs can be advanced by understanding the body's realistic dimensional changes during exercise. No published research analyses the body's dimensional changes or range of movement during exercise as a foundation for garment development [11]. To fulfil the aim of this study and test the hypothesis, 3D and 4D scan technologies were used to capture the human body in static and dynamic postures. For this study six amateur female football players were recruited from a team in Germany, to examine the dimensional variations that occur in the body when in motion. For the first part of the study, professional female football players in action were observed to determine recurrent postures during play, and two were chosen to analyse and compare against the manual measurements as well as each other, using 3D scan technology. The six participants were scanned in the two postures, their body dimensions will be obtained, and fluctuations evaluated. Although this method aims to improve the understanding of dimensional changes, can it demonstrate realistic values? The second part of the research involves answering this question, by using $4 \mathrm{D}$ scan technology to capture the body while it is in motion and further contrasting these measurement values, with those obtained by using functional static postures in the 3D scanner. The hypothesis, based on the following literature review, is that results will highlight

\footnotetext{
* Kasey Hatch, PhD Researcher, University of Manchester, kasey.hatch@postgrad.manchester.ac.uk
} 
great differences in muscle proportions between the relaxed and functional postures as well as the 4D dynamic body positions. Therefore, exploring the limitations with using static body measurements captured through 3D body scanning for application in the design of sportswear, and the possibilities of future enhancement utilising 4D motion scanning [11].

\section{Literature Review}

\subsection{Sports Compression Garments}

Sports compression garments (SCGs) are garments designed for sports application, that fit tightly to the body, in order to apply pressure to the skin and underlying tissue [16]. Professional and amateur athletes wear these garments [17] in order to improve performance, aid recovery and prevent injuries [18]. However, effects of SCGs have been controversial; studies show mixed results regarding the physiological and psychological benefits $[19,20]$. The garments primarily work by the applied pressure narrowing veins and forcing blood flow back to the heart, increasing circulation [21]. As circulation is increased, more oxygenated blood is delivered to the muscles, muscles require a greater amount of oxygen during exercise, so this reduces lactic acid build-up [30] and reduces muscle fatigue [23]. Other physical and psychological benefits include reduced muscle oscillation [30], enhanced proprioception [23] and reduction in perceived muscle soreness during recovery [31] due to the lack of lactic acid build up in the muscle fibres. In order for SCGs to function, they need to have a tight enough fit to be able to exert pressure on the body, therefore fit optimisation is extremely important. If the garment is too loose, little to no pressure is applied and benefits will not be felt. On the other hand, if the garments are too tight, the resulting pressure can cause damage to the wearer [22]; circulation can become restricted, causing excessive discomfort and numbness [23] which will result in fatigue and effect heart and lung function [24]. Research into the fit of SCGs is neglected, which could be why the effects have demonstrated such inconsistencies in previous studies.

\subsection{Sizing and Fit}

Despite the importance of fit, there is currently only one published research paper evaluating sizing methodologies for SCGs [16], which demonstrates a lack of understanding of compression garment mechanisms [25]. There is also a paucity of theoretical research in stretch pattern cutting, and what is available simply adapts woven patterns but removing the darts and deducting an amount (\%) of the pattern to compensate for the stretch $[7,8]$. The woven pattern cutting that is currently the foundation for stretch pattern cutting, still lacks research and connection between pattern and body [39]. It is assumed that the elasticity of the knitted fabric will stretch to fit a variety of body shapes and sizes, without the need for adjustments that are required for woven garments [8]. There is currently no theory to underpin the sizing and grading of stretch garments.

Proportional dressmaker's systems were established between 1820-1840 [26], they are sizing systems that are solely based on the measurements of a fit model, chosen to represent the target consumer [40]. The body dimensions of the individual are used to create patterns, to which grade rules are applied in order to make smaller and larger sizes. In industry this is the most popular grading method because of its practicality and cost-effectiveness, however because this method is based on measurements and allowances for the fit model, it will not be able to accommodate a large and varied population [27]. Only the individuals whose body proportions are identical to the fit model will experience perfect fit [40]. Sizing systems are usually based on minimal body dimensions and rely on the assumption of proportional relationships between body measurements to calculate other dimensions [28], however this approach has been doubted [28,29]. During the first U.S anthropometric survey in 1941, no one measurement was identified that could be utilised to calculate the other body measurements and the bust girth and stature were "almost entirely unrelated" [29]. Key dimensions are body measurements selected for use in size charts to divide the population into size designations [35]. They are chosen as they correlate with other dimensions required for patten drafting and they will be easily measured [35]. For sports compression leggings, height and weight are commonly used as key dimensions, which is based on sizing systems for hosiery. Although they are easily measured by the consumer, the measurements may not take into consideration the size and shape of the limb which effects pressure delivery [37]. Instead of using proportional grading theories and height and weight as key dimensions, more research is required to understand which body measurements are essential for optimal fit and pressure delivery and the body dimensions of the target market. 


\subsection{Motion Centred Design}

As aforementioned, it is necessary to think about the target demographic when designing SCGs, especially thinking about the moving body. Individual's range and speed of motion varies due to factors such as age, gender, health, fitness, and body morphology [10]. Movement as well as the factors that can affect an individual's mobility is often not considered during product development of SCGs $[3,11]$ and the only published research focusing on movement related ease is for woven garments $[4,5,6]$. Ease is defined as the dimensional difference between the garment and the contour of the body [11], which can either be positive or negative; SCGs have negative ease as the garment is designed to be smaller than the body dimensions. Ease requirements will also vary whilst moving, as the allowance transfers from one area of the garment to another [9]. Dynamic ease distribution has been neglected by current research [9].

During physical activity, the body's muscles contract and relax in opposing areas. This muscle action as well as flexion, extension, abduction, and adduction of joints will continuously alter the body's dimensions $[10,11]$, the skin and the surrounding skin will react. When a muscle contracts, it shortens and expands, the overlaying SCG will stretch simultaneously and an increase in pressure will be forced onto the skin. For this reason, pressures applied by the SCGs on the body will fluctuate during movement. The amount of pressure that a SCG can put on the body is dependent on body morphology (size and shape), which relates to Laplace's Law. Laplace's Law describes pressure, its relationship to tension [34] and its negative correlation the radius of a cylindrical object [33]. Therefore, if the tension in the garment is constant, the pressure magnitude will increase as the radius of the limb decreases. This theory only quantifies static pressure; when moving the tension in the fabric is no longer constant and is ever changing. This effects pressure exertion and can make it much more difficult to predict. A better understanding of biomechanics and body morphology is needed to design SCGs that generate a consistent graduated pressure profile without potentially harmful extreme pressures or pressures which are too low to have an effect. If applied pressures in motion can be predicted, alterations can be made to the knitted fabric itself and the pattern to create optimal fit. 3D scanning allows the capture of the body in static functional postures, which has been done in previous studies $[2,4,10,13]$, to determine functional ease requirements for pattern development. However, there are limitations to the accuracy of the results if the intention is to replicate movement $[10,11,14,15]$. As the body moves into and holds the static, functional postures, the body tenses muscles that may not necessarily be utilized when the body in performing the natural movement [11]. The static functional postures are rarely assumed in reality as the simple movements consist of the controlled isolated movement of a single joint. Whereas when the body is organically moving, multiple joints work cohesively to create fluid movements. It is questionable if $3 \mathrm{D}$ scanning of static functional postures is the most accurate representation of dimensional changes. The solution to the accuracy of the data could be 4D scanning, which the Hohenstein Institute have explored in their 'Restriction of Mobility' project completed in 2020 [11]. Their study concluded that further studies into the use of 4D scanning for clothing development is needed as currently only moderate movement speeds can be recorded but it is limited by its affordability.

\section{Method}

\subsection{Participants}

Female football players have been selected as the participants and target consumers for this study, as through observation of women's professional football, the adoption of SCGs by the athletes appears to be virtually non-existent during matches, in comparison to their male counterparts. It appears that male football players wear both upper and lower body compression garments during training and matches as well as recovery, whereas females seem to use compression socks alone. The reason for their lack of use by females is unclear, however it could be due to a lack of money invested in this sport (when compared to men's football), or knowledge about the benefits of their use, or previous experiences having no effect on performance, which could be a result of poor fitting garments. There are no studies that have evaluated the effects of SCGs on female football players. Six female German amateur football players with an average age of $19.33 \pm 3.82$ years, were recruited by Hohenstein for this study. Participants were required to be $16+$ years old, so they were old enough to play women's $11 \mathrm{v} 11$ football [36]. It was also important that they were currently active, engaged in regular physical activity. They were required to read and sign an online consent form as well as filling in a short online questionnaire prior to the scan procedure. 


\subsection{Determination of Key Dimensions}

An understanding of the dimensions needed for product development is imperative. Sports compression leggings require limb circumference measurements in order to provide consistent pressure across the leg; waist, hip, thigh, knee, calf and ankle circumference measurements have been extracted from the scans for comparison. No vertical measurements were chosen for extraction at this stage.

\subsection{Scan Postures}

The postures were chosen as they are frequently performed by football players. Game-play analysis of movements, highlighted running as the most regular motion, therefore the functional postures selected were two positions acted during the running gait cycle, and the dynamic posture captured by the 4D scanner would be during running. To communicate these positions to the participants, instructional posters were designed and placed around the scan space as a visual aid.

\subsubsection{Functional static postures}

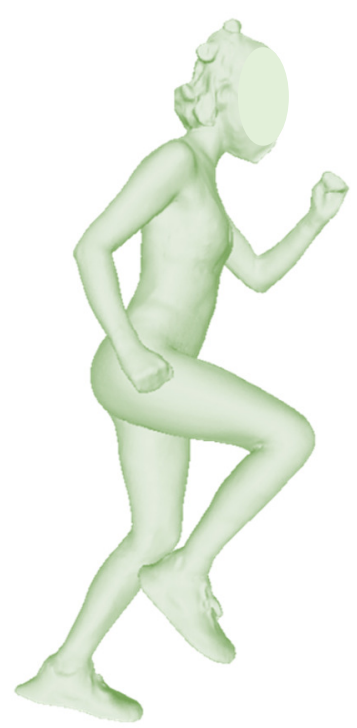

Figure 1. Participant 002 scanned in posture one.

Scan posture one: 'Take-off' point, performed in the swing and stance phase of the gait cycle, at which one leg is using the most force to push forward off the floor.

Table 1. Definition of posture one

\begin{tabular}{|l|l|l|}
\hline \multicolumn{1}{|c|}{ Joint } & \multicolumn{1}{|c|}{ Type of Movement } & \multicolumn{1}{c|}{ Degree of Movement } \\
\hline Hip (R) & Flexion & 90 \\
\hline Knee (R) & Flexion & 60 \\
\hline Ankle (R) & Dorsiflexion & 20 \\
\hline Hip (L) & Extension & 45 \\
\hline Knee (L) & Flexion & 20 \\
\hline Ankle (L) & Dorsiflexion & 20 \\
\hline
\end{tabular}




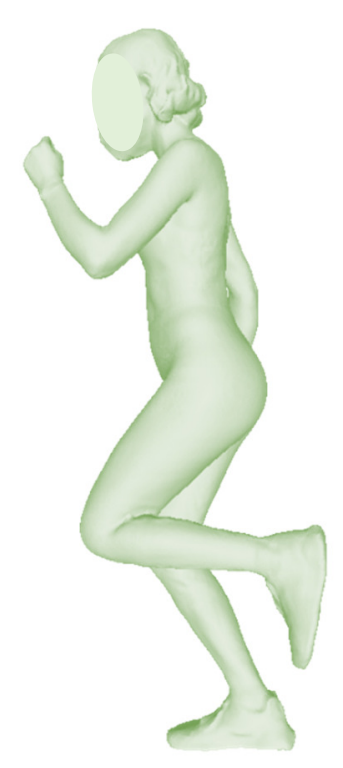

Figure 2. Participant 002 scanned in posture two.

Scan posture two: 'Heel contact' point (first/last) of the gait cycle, where one heel comes in contact with the floor.

Table 2. Definition of posture two

\begin{tabular}{|l|l|l|}
\hline \multicolumn{1}{|c|}{ Joint } & \multicolumn{1}{|c|}{ Type of Movement } & \multicolumn{1}{c|}{ Degree of Movement } \\
\hline Hip (R) & Flexion & 45 \\
\hline Knee (R) & Flexion & 20 \\
\hline Ankle (R) & Dorsiflexion & 20 \\
\hline Hip (L) & Extension & 20 \\
\hline Knee (L) & Flexion & 135 \\
\hline Ankle (L) & Plantarflexion & 20 \\
\hline
\end{tabular}

\subsubsection{Dynamic posture}

Participants were required to perform a steady run as per the gait cycle shown in Figure 1. It was essential that the movement was as natural as possible to accurately compare against the other postures. To achieve the dynamic posture, a treadmill was used to capture the running motion in the confined space, to control the speed of the participants and to allow realistic movement.

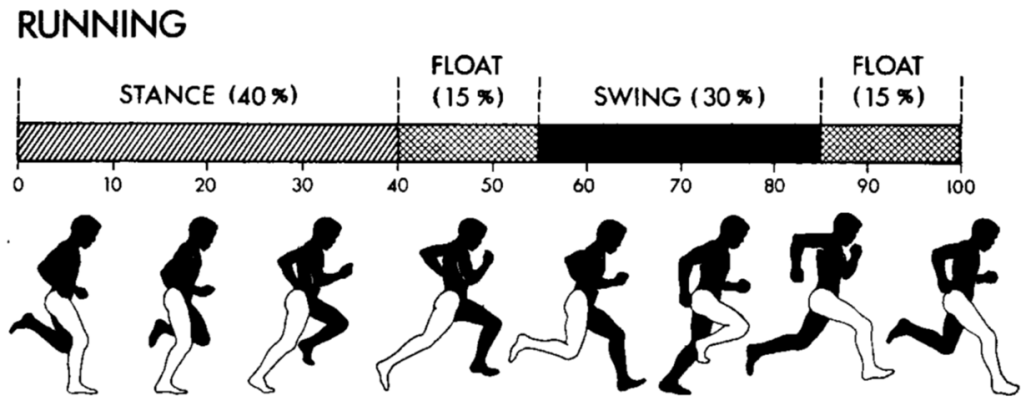

Figure 3. Phases of the running gait cycle [38]

\subsection{Data Collection}

\subsubsection{Questionnaire}

Qualtrics online survey tool was used to create the consent form and questionnaire and QR codes for these were located in the scan space for participants to scan. Each participant read through the consent form, input their ID number, which they were given to maintain anonymity, and agreed to the statements. The questionnaire was subsequently completed by answering questions about themselves and their manual measurements were input . 
The questionnaire asked for the participant's age and nationality. Height and weight were also requested and were measured using a scale (weight) and a tape measure (height). As well key circumferential measurements were taken to give an initial idea of the differences in lower-limb profiles of the participants and to assess whether the frequently used proportional grading systems mentioned in section 2.1 would be appropriate for this female population. Means of the height, weight, and circumferential measurements were calculated, as well as the standard deviation. The participants were also asked to confirm how many hours of exercise they perform in an average week, to check they were regularly active. The National Health Service (NHS) states that adults should perform at least 150 minutes (2 hours 30 minutes) of moderate activity or 75 minutes ( 1 hour 15 minutes) of vigorous activity to stay active and considers sports such as football to be a vigorous intensity activity [32]. To further support the study, the subjects were asked whether they currently use SCGs for training, matches or recovery; it is previously mentioned in section 3.1 that female football players have not been observed using SCGs for match purposes. This question allows for validation of the observations and opportunity to know if they are being used for alternative purposes. This project aims to aid the production of sports compression leggings for female football players, by determining the changes to body dimensions during movement, so it is important that there is a market for this product for the target demographic. Therefore, the women were also questioned whether they would use a pair of sports compression leggings for either training, matches or recovery.

\subsubsection{Scan Procedure}

Each participant was scanned at the Hohenstein offices in Bönnigheim, Germany, using the 3D Vitus Smart Laser scanner (Human Solutions GmbH, Germany) and 'Little Alice' 4D scanner, (Sample \& Hold, UK) following the institutional scan protocol. First manual measurements were taken of each subject's height, weight, and key circumferences (waist, hip, thigh, knee and ankle). During both manual measuring and scanning, participants wore their own tights/leggings, and any garments worn on the top half of the body should not interfere with accurate measurement of the waist. Instructional imagery was displayed in the scan space to aid participants into each position, which was then checked with a goniometer. ScanWorx (Human Solutions $\mathrm{GmbH}$, Germany) was used to capture the scan information from the 3D Vitus Smart Laser Scanner and the 'Little Alice 4D scanner.

\subsection{Data Analysis}

Analysis of collected data involved using Size Stream Studio software (Size Stream LLC, USA) for the comparison of each player's manual circumferential measurements and the scans in the functional postures, examining the changes in measurement that are required for the pattern cutting and grading of sports compression leggings. The next stages of analysis will include comparing the key dimensions of the functional postures with the same dimensions of the corresponding dynamic posture. The analysis seeks to understand the extent to which the lower body dimensions change from static to dynamic postures to determine the best method of capturing anthropometric data for SCG sizing and grading.

\section{Preliminary Results}

\subsection{SCG Use}

The six participants are active females who complete up to ten hours of physical activity per week. All six do not currently use any sports compression garments for any part of their exercise routine, which reiterates the fact that SCG use in female football is minimal. However, when asked how they would use sports compression leggings in their routine, no participant selected the 'I would not wear them' response, suggesting that the explanation is not that they do not want to wear them. Only one (16.67\%) of the subjects indicated that she would be interested in wearing sports compression leggings during recovery, suggesting that this is not a consideration for these women, they may already have good recovery methods that suit them or are less aware of the benefits to recovery than performance. Two (33.33\%) participants would use the leggings for training, and four $(66.67 \%)$ would wear the leggings during matches. Improving performance is clearly the motivation for these women to wear compression leggings, which is important for product development. 


\subsection{Manual Measurements}

Table 3. Manual measurements taken of the six participants

\begin{tabular}{|c|c|c|c|c|c|c|}
\hline $\begin{array}{c}\text { Participant } \\
\text { ID }\end{array}$ & $\begin{array}{l}\text { Height } \\
(\mathrm{cm})\end{array}$ & $\begin{array}{l}\text { Weight } \\
(\mathrm{Kg})\end{array}$ & $\begin{array}{c}\text { Waist } \\
\text { Circumference } \\
(\mathrm{cm})\end{array}$ & $\begin{array}{c}\text { Hip } \\
\text { Circumference } \\
\text { (cm) }\end{array}$ & $\begin{array}{c}\text { Knee } \\
\text { Circumference } \\
(\mathrm{cm})\end{array}$ & $\begin{array}{c}\text { Ankle } \\
\text { Circumference } \\
\text { (cm) }\end{array}$ \\
\hline 001 & 162.8 & 57 & 71 & 100 & 35.5 & 23.5 \\
\hline 002 & 158.3 & 47 & 70 & 90 & 33 & 20.5 \\
\hline 003 & 161.5 & 48 & 64 & 93.5 & 31.5 & 21 \\
\hline 004 & 172 & 57 & 68.5 & 89 & 34 & 20.5 \\
\hline 005 & 158 & 52 & 71 & 95 & 32.5 & 21 \\
\hline 006 & 168.1 & 58.6 & 70 & 95 & 37.5 & 23 \\
\hline Mean & 163.45 & 53.27 & 69.08 & 93.75 & 34.00 & 21.58 \\
\hline SD & \pm 5.09 & \pm 4.56 & \pm 2.42 & \pm 3.63 & \pm 2.00 & \pm 1.20 \\
\hline
\end{tabular}

Manual measurements were taken, to give the key circumferential dimensions of the participants which provided an initial overview of the difference in body morphology of each participant as well as the measurements needed to compare to the scan data. These are shown in Table 1. The subject age range is 16-27, however this has displayed no effect on height, weight, and circumferential measurements. Statistical analysis of the measurements was conducted to find the correlation coefficients $(r)$ of pairs of variables and determine the strength of the relationship between them. Each variable was analysed against the rest of the measurements taken. All but two correlation values are positive, suggesting a linearity in the relationship between most of the variables. All circumferential dimension correlations range between 0.31 and 0.85 , the strongest relationship $(r=0.85)$ being between hip and ankle circumferences. Negative correlation occurs between height and waist circumference ( $r=$ $-0.10)$ and height and hip circumference $(r=-0.23)$. Only two (weight and knee circumference) of the five variables compared with height had a moderate positive correlation, showing that height has little relationships with circumferential measurements. Regression analysis was then carried out on the relationship involving height and the independent variables, weight, and knee circumference to establish whether these connections have significance. To show significance p-values must be less than 0.05 . Neither weight $(p=0.26)$ or knee circumference $(p=0.76)$ has a $p$-value less than 0.05 . It is likely that this relationship is coincidence. As aforementioned proportional grading methods use the theory that as height increases, so does weight and other key dimensions; from the dimensional data in Table 1, it would indicate that this method would not be appropriate method to create sizing systems for the sports compression leggings. The tallest participant (ID: 004), is not the heaviest, nor has the largest waist, hip, knee, or ankle circumferences. The same is true for the shortest participant (ID: 005).

\subsection{D Scanning}

Each scan was viewed using Size Stream Studio (Size Stream LLC, USA), the chosen dimensions were then extracted manually rather than automatically by the software. Size Stream as well as other scanning software do not allow for auto-extraction of measurements of non-normative postures. The functional postures are not recognised in the same way as the standard scan posture, which can create problems for analysis, as the lack of measurement automation could impair the accuracy that 3D scanning is used for. The measurements were then retrieved by manually plotting the circumferences and the software calculating the dimensions in two ways; one including all the body contours and another as though it were taken using a tape measure. Only the contour measurements are being used for analysis as the SCGs are tight enough to conform to the body's contours. The limb circumferences were taken from the leg that was engaged in the biggest change or 'movement', so the left leg measurements were taken from posture one and right leg measurements were taken from posture two (Figures 1 and 2). Measurements were exported to Microsoft Excel (Microsoft Corporation, USA) for evaluation. Tables 4 and 5 show the contour measurements of each of the six participants. Participants 004 and 005 are missing in Table 4 as both of their first postures were unable to be analysed due to an unknown error in the scans. 
Table 4. 3D functional measurements taken of the six participants in posture 1

\begin{tabular}{|c|c|c|c|c|c|c|r|r|}
\hline $\begin{array}{c}\text { Measurement } \\
(\mathrm{cm})\end{array}$ & 001 & 002 & 003 & 004 & 005 & 006 & Mean & SD \\
\hline $\begin{array}{c}\text { Waist } \\
\text { Circumference }\end{array}$ & 77.50 & 70.98 & 68.05 & - & - & 78.21 & 73.69 & \pm 4.31 \\
\hline $\begin{array}{c}\text { Hip } \\
\text { Circumference }\end{array}$ & 95.67 & 94.40 & 92.93 & - & - & 92.12 & 93.78 & \pm 1.36 \\
\hline $\begin{array}{c}\text { Thigh } \\
\text { Circumference }\end{array}$ & 48.00 & 46.87 & 46.45 & - & - & 54.58 & 48.98 & \pm 3.29 \\
\hline $\begin{array}{c}\text { Knee } \\
\text { Circumference }\end{array}$ & 44.44 & 41.82 & 39.75 & - & - & 44.16 & 42.54 & \pm 1.91 \\
\hline $\begin{array}{c}\text { Calf } \\
\text { Circumference }\end{array}$ & 35.23 & 34.17 & 32.49 & - & - & 38.07 & 34.99 & \pm 2.03 \\
\hline $\begin{array}{c}\text { Ankle } \\
\text { Circumference }\end{array}$ & 22.18 & 20.80 & 22.37 & - & - & 22.66 & 22.00 & \pm 0.71 \\
\hline
\end{tabular}

Table 5. 3D functional measurements taken of the six participants in posture 2

\begin{tabular}{|c|c|c|c|c|c|c|r|r|}
\hline $\begin{array}{c}\text { Measurement } \\
(\mathrm{cm})\end{array}$ & 001 & 002 & \multicolumn{1}{c|}{003} & \multicolumn{1}{c|}{004} & 005 & \multicolumn{1}{c|}{006} & Mean & SD \\
\hline $\begin{array}{c}\text { Waist } \\
\text { Circumference }\end{array}$ & 72.32 & 70.18 & 67.31 & 73.87 & 75.97 & 75.35 & 72.50 & \pm 3.01 \\
\hline $\begin{array}{c}\text { Hip } \\
\text { Circumference }\end{array}$ & 97.13 & 89.26 & 90.03 & 90.14 & 93.18 & 91.05 & 91.80 & \pm 2.68 \\
\hline $\begin{array}{c}\text { Thigh } \\
\text { Circumference }\end{array}$ & 53.41 & 49.35 & 47.27 & 50.32 & 50.50 & 54.47 & 50.89 & \pm 2.42 \\
\hline $\begin{array}{c}\text { Knee } \\
\text { Circumference }\end{array}$ & 43.04 & 44.29 & 44.48 & 44.17 & 43.65 & 44.65 & 44.04 & \pm 0.55 \\
\hline $\begin{array}{c}\text { Calf } \\
\text { Circumference }\end{array}$ & 36.83 & 35.94 & 33.87 & 36.74 & 35.24 & 40.34 & 36.49 & \pm 1.99 \\
\hline $\begin{array}{c}\text { Ankle } \\
\text { Circumference }\end{array}$ & 21.51 & 21.22 & 22.17 & 22.45 & 20.04 & 24.21 & 21.93 & \pm 1.28 \\
\hline
\end{tabular}

There were substantial differences between the manual measurements and the extracted measurements from the functional postures, especially for participant 001 . The subject's knee circumference increased by $8.94 \mathrm{~cm}$ from standing in the standard position (manual measure) to posture one, and $7.54 \mathrm{~cm}$ to posture two. For all six participants, waist and knee circumferences increased from manual measuring to both postures one and two, which is most likely due to the abdominal muscles engaging to hold the body in the functional postures, slightly leaning forward and holding the elevated leg. The knee expansion is due to the joint flexion, protruding the patella and the webbing that occurs in the scan as the gastrocnemius muscles in the calf and biceps femoris muscles in the thigh, make contact. The ankle dimensions were the most difficult to analyse, some participant's manual measurements were smaller than in functional postures and others were larger, demonstrating no pattern in the results. Potential causes of this could be the fact that it was not always easy to precisely locate the ankle, due to the socks, leggings and shoes worn obstructing the contours of the ankle area. $88.9 \%$ of functional hip circumferences recorded were narrower than their manual equivalents, which could be a result of the weight being transferred onto the supporting leg and lowering the hip to stabilise, which would not be necessary during dynamic movement. 


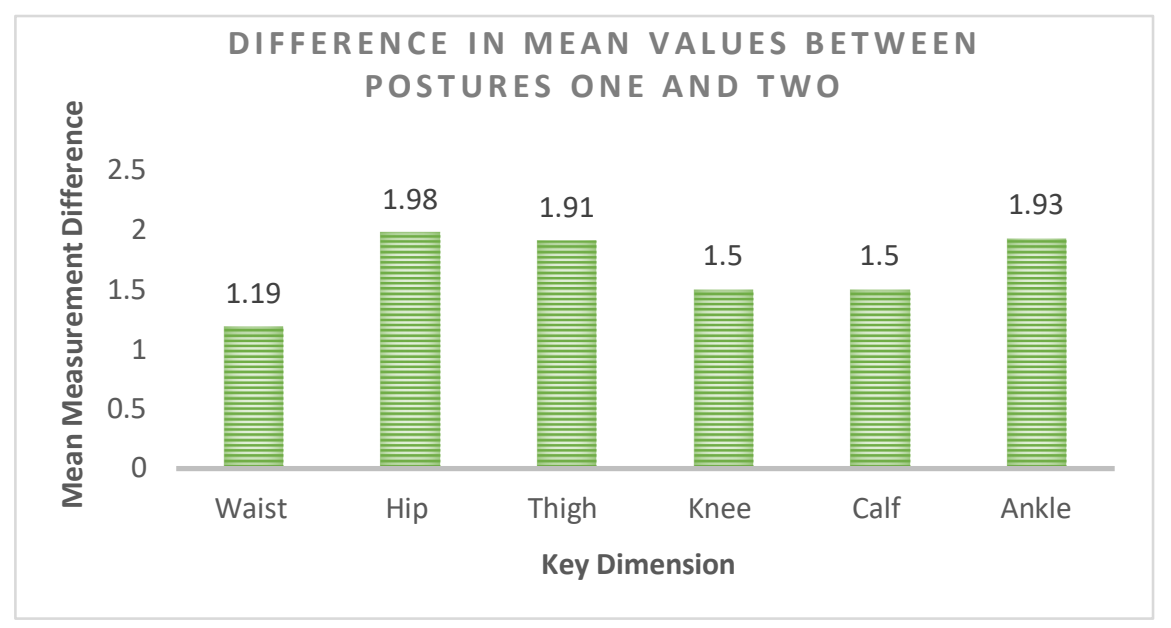

Figure 4. Difference in mean values of each key dimension measured between the functional postures one and two.

Variations were noted between postures one and two also. Although the two different stages in the running gait cycle are similar; one foot is in contact with the floor, and the hip, knee and ankle have all moved, the differences in circumferential measurement are as great as $5.41 \mathrm{~cm}$ at the thigh of participant 001. The mean values for each dimension in both postures one and two are not largely dissimilar, Figure 4 displays these differences which are all between $1.19-1.98 \mathrm{~cm}$. Not only are there small inter-postural differences in mean values, but all of the differences are also within a range of $0.79 \mathrm{~cm}$. Despite minimal variation, fit and pressure delivery will be impacted so it is important to understand the location and degree of change.

\section{Conclusion}

Currently only the first stage of this study is complete, so conclusions cannot be made as to whether 4D scanning provides more accurate body measurements than using 3D scanning of functional postures yet. However, with the results of the manual measuring and the 3D body scanning it is clear that lower body dimensions vary considerably when moving into different positions. The degree to which these measurements changed may be unrealistic due to the body having to hold itself in a static pose rather than being constantly in motion. Despite this it is evident that in order to produce sport compression leggings that fit sufficiently, movement must be a consideration in the design and development process and the dimensional fluctuations will affect the level of pressure on the skin.

There has been limitations to this study, which has questioned the accuracy of measurement. Manually extracting the body dimensions from the scans is challenging to achieve consistency across every scan, therefore there is a need to adapt software so that it can auto-extract measurements from functional postures to improve accuracy of measurement. Alternative programmes will be tested to achieve this. Accuracy may be improved by removing the clothing and footwear worn by the subjects, and scanning in their underwear only, so that body contours can be easily located, and no extra bulk is measured. This experimental study is small-scale, with only six participants, therefore the results do not represent the female football population as a whole. All six subjects in the study share the same ethnicity; results may differ if the participants were all different due to anthropometric differences between nations. Larger studies of active female football players from various ethnic backgrounds, are needed to provide a clearer insight into body morphology of female football players.

\section{References}

[1] Choi, S., \& Ashdown, S. p. (2011). 3D body scan analysis of dimensional change in lower body measurements for active body positions. Textile Research Journal, 81(1), 81-93. https://doi.org/10.1177/0040517510377822

[2] Dabolina, I., Lapkovska, E., \& Vilumsone, A. (2019). Functional Textiles and Clothing. In Functional Textiles and Clothing. Springer Singapore. https://doi.org/10.1007/978-981-13-7721-1

[3] Gupta, D. (2019). New directions in the field of anthropometry, sizing and clothing fit. In Anthropometry, Apparel Sizing and Design (2nd ed.). Elsevier Ltd. https://doi.org/10.1016/B978-0-08-102604-5.00001-9 
[4] Jolly, K., Krzywinski, S., Rao, P. V. M., \& Gupta, D. (2019). Kinematic modeling of a motorcycle rider for design of functional clothing. International Journal of Clothing Science and Technology, 31(6), 856-873. https://doi.org/10.1108//JCST-02-2019-0020

[5] Gill, S., \& Hayes, S. (2012). Lower body functional ease requirements in the garment pattern. International Journal of Fashion Design, Technology and Education, 5(1), 13-23. https://doi.org/10.1080/17543266.2011.593560

[6] Watkins, S. M. (1977). The Design of Protective Equipment for Ice Hockey. Home Economics Research Journal, 5(3), 154-166. https://doi.org/10.1177/1077727X7700500303

[7] Varghese, N., \& Thilagavathi, G. (2015). Development of woven stretch fabrics and analysis on handle, stretch, and pressure comfort. Journal of the Textile Institute, 106(3), 242-252. https://doi.org/10.1080/00405000.2014.914652

[8] Dove, T. (2016). Stretch to fit - made to fit†. International Journal of Fashion Design, Technology and Education, 9(2), 115-129. https://doi.org/10.1080/17543266.2016.1167252

[9] Liu, Z., He, Q., Zou, F., Ding, Y., \& Xu, B. (2019). Apparel ease distribution analysis using threedimensional motion capture. Textile Research Journal, 89(19-20), 4323-4335. https://doi.org/10.1177/0040517519832842

[10] Morlock, S., Loercher, C., \& Schenk, A. (2019). Motion-oriented 3D analysis of body measurements. IOP Conference Series: Materials Science and Engineering, 254(17), 22-23. https://doi.org/10.1088/1757899X/254/17/172016

[11] Klepser, A., Morlock, S., Loercher, C., \& Schenk, A. (2019). Functional measurements and mobility restriction (from 3D to 4D scanning). In Anthropometry, Apparel Sizing and Design (2nd ed., Issue 2018). Elsevier Ltd. https://doi.org/10.1016/B978-0-08-102604-5.00007-X

[12] Ernst, M., \& Detering-Koll, U. (2014). Posture Dependency of 3D-Body Scanning Data for a Virtual Product Development Process in Apparel Industry. October, 248-258. https://doi.org/10.15221/14.248

[13] Vasile, S., Cools, J., De Raeve, A., Malengier, B., \& Deruyck, F. (2019). Effect of rowing posture on body measurements and skin-sportswear interface pressure and implications on garment fit. Journal of Industrial Textiles, 152808371987700. https://doi.org/10.1177/1528083719877005

[14] Chi, L., \& Kennon, R. (2006). Body scanning of dynamic posture. International Journal of Clothing Science and Technology, 18(3), 166-178. https://doi.org/10.1108/09556220610657934

[15] Aldrich, W., Smith, B., \& Feng Dong. (1998). Obtaining repeatability of natural extended upper body positions: its use in comparisons of the functional comfort of garments. Journal of Fashion Marketing and Management, 2(4), 329-351. https://doi.org/10.1108/eb022538

[16] Brubacher, K. (2020). Comparison and Evaluation of Sizing Systems Used in Commercial Women's Compression Sportswear. Proceedings, 49(1), 140. https://doi.org/10.3390/proceedings2020049140

[17] Fu, W., Liu, Y., Zhang, S., Xiong, X., \& Wei, S. (2012). Effects of local elastic compression on muscle strength, electromyographic, and mechanomyographic responses in the lower extremity. Journal of Electromyography and Kinesiology, 22(1), 44-50. https://doi.org/10.1016/j.jelekin.2011.10.005

[18] Kraemer, W. J., Bush, J. A., Newton, R. U., Duncan, N. D., Volek, J. S., Denegar, C. R., Canavan, P., Johnston, J., Putukian, M., \& Sebastianelli, W. J. (1998). Influence of a compression garment on repetitive power output production before and after different types of muscle fatigue. Sports Medicine, Training and Rehabilitation, 8(2), 163-184. https://doi.org/10.1080/15438629809512525

[19] Engel, F., \& Sperlich, B. (2016). Compression garments in sports: Athletic performance and recovery. Compression Garments in Sports: Athletic Performance and Recovery, December 2018, 1-111. https://doi.org/10.1007/978-3-319-39480-0

[20] MacRae, B. A., Cotter, J. D., \& Laing, R. M. (2011). Compression garments and exercise: Garment considerations, physiology and performance. Sports Medicine, 41(10), 815-843. https://doi.org/10.2165/11591420-000000000-00000

[21] Liu, R., Guo, X., Lao, T. T., \& Little, T. (2017). A critical review on compression textiles for compression therapy: Textile-based compression interventions for chronic venous insufficiency. Textile Research Journal, 87(9), 1121-1141. https://doi.org/10.1177/0040517516646041

[22] Mosti, G., \& Partsch, H. (2010). Is low compression pressure able to improve venous pumping function in patients with venous insufficiency? Phlebology, 25(3), 145-150. https://doi.org/10.1258/phleb.2009.009023

[23] Xiong, Y., \& Tao, X. (2018). Compression garments for medical therapy and sports. Polymers, 10(6), 1-20. https://doi.org/10.3390/polym10060663

[24] Wang, Y., \& Zhang, P. (2013). The effect of physical-mechanical properties on dynamic pressure of compression garment. International Journal of Clothing Science and Technology, 25(2), 131-144. https://doi.org/10.1108/09556221311298637

[25] Brubacher, K. (2018). Towards the design of sports compression garments with controlled pressure. Manchester Metropolitan University.

[26] Kidwell, C. B. (1979). Cutting a Fashionable Fit: Dressmakers' Drafting Systems in the United States. Smithsonian Studies in History and Technology, 42, 1-163. https://doi.org/10.5479/si.00810258.42.1 
[27] Petrova, A., \& Ashdown, S. P. (2012). Comparison of Garment Sizing Systems. Clothing and Textiles Research Journal, 30(4), 267-284. https://doi.org/10.1177/0887302X12463603

[28] Ashdown, S. P. (1998). An investigation of the structure of sizing systems. A comparison of three multidimensional optimized sizing systems generated from anthropometric data with the ASTM standard D5585-94. International Journal of Clothing Science and Technology, 10(5), 324-341. https://doi.org/10.1108/09556229810239324

[29] O'Brien, R. , \& Shelton, W. C. (1941). Women's measurements for garment and pattern construction. Misc. Pub. 454 Textiles and Clothing Division of Bureau of Home Economics, U.S. Dept. of Agriculture in coop with Work Projects Administration. Washington, DC: U.S. Government Printing Office.

[30] Allsop, C. (2012). An Evaluation of Base Layer Compression Garments for Sportswear. Manchester Metropolitan University.

[31] Jakeman, J. R., Byrne, C., \& Eston, R. G. (2010). Lower limb compression garment improves recovery from exercise-induced muscle damage in young, active females. European Journal of Applied Physiology, 109(6), 1137-1144. https://doi.org/10.1007/s00421-010-1464-0

[32] The NHS. (2021). Exercise: Physical activity guidelines for adults aged 19 to 64. https://www.nhs.uk/livewell/exercise/

[33] Ramelet, A.-A. (2002). Compression Therapy. Dermatologic Surgery, 28(1), 6-10. https://doi.org/10.1046/j.1524-4725.2002.01181.x

[34] Troynikov, O., Ashayeri, E., Burton, M., Subic, A., Alam, F., \& Marteau, S. (2010). Factors influencing the effectiveness of compression garments used in sports. Procedia Engineering, 2(2), 2823-2829. https://doi.org/10.1016/j.proeng.2010.04.073

[35] Bradtmiller, B. (2013). Scan-to-Pattern Clothing Systems: A Systematic Approach. November, 379-383. https://doi.org/10.15221/13.379

[36] The Football Association. (n.d.). Play Womens or Girls Football. Retrieved August 13, 2021, from https://www.thefa.com/womens-girls-football/get-involved/play-football

[37] Hill, J. A., Howatson, G., van Someren, K. A., Davidson, S., \& Pedlar, C. R. (2015). The variation in pressures exerted by commercially available compression garments. Sports Engineering, 18(2), 115-121. https://doi.org/10.1007/s12283-015-0170-x

[38] Adelaar, R. S. (1986). The practical biomechanics of running. The American Journal of Sports Medicine, 14(6), 497-500. https://doi.org/10.1177/036354658601400613

[39] Bye, E., Labat, K. L., \& Delong, M. R. (2006). Analysis of Body Measurement Systems for Apparel. Clothing and Textiles Research Journal, 24(2), 66-79. https://doi.org/10.1177/0887302X0602400202

[40] Ashdown, S. P. (2014). Creation of ready-made clothing: the development and future of sizing systems. In Designing Apparel for Consumers (Vol. 10, Issue 5, pp. 17-34). Elsevier.

https://doi.org/10.1533/9781782422150.1.17 